\title{
Representation of Gamblers in the Singaporean Press since Casino Legalization: A Corpus-driven Critical Analysis
}

\author{
Ray C. H. Leung \\ Department of English and American Studies, University of Potsdam, Am Neuen Palais 10, 14469 Potsdam, Germany \\ E-mail: chungleungde@gmail.com
}

Received: 13-05-2016

Accepted: 27-07-2016

Published: 01-11-2016 doi:10.7575/aiac.ijalel.v.5n.6p.51

Advance Access Published: September 2016

URL: http://dx.doi.org/10.7575/aiac.ijalel.v.5n.6p.51

\begin{abstract}
Capitalizing on the lack of gambling-related research among discourse analysts and the recent liberalization of casino operations in Singapore, the present article reports on the discursive representation of gamblers in Singapore newspaper texts by merging corpus linguistics and critical discourse analysis. 889 articles from the popular daily paper The Straits Times (Singapore) were retrieved via LexisNexis in accordance with a series of criteria. The extracted texts, which were dated from 17 April 2005 to 28 April 2013, constitute the 615 827-word corpus of the current study. WordSmith Tools 6.0 was used to perform collocation analysis, which was enriched by critical examination of the concordance lines. The findings indicate that apart from gender stereotyping, social alienation is manifested in various ways while gamblers are being portrayed. For instance, the pronoun collocate 'we' of the node 'gambler*' tends to signify the non-gamblers' voice which is geared towards the institutional stance. The verb collocate 'say' is frequently used in contexts where the gamblers are being commented upon or criticized. The analytic outcomes of the research have once again confirmed the 'hegemonizing' character of newspaper texts.
\end{abstract}

Keywords: critical discourse analysis, gamblers, Singaporean press, corpus linguistics, institutionally constructed identities, collocation

\section{Introduction}

In the scholarly domain, gambling appears to be a topic which primarily concerns sociologists, psychologists and fellow researchers in cultural studies. The edited volume The Sociology of Risk and Gambling Reader by Cosgrave (2006), for instance, contains articles from sociologists who analyzed gambling-related issues from the perspective of public administration and societal risk. A search of the two journals specialized in gambling-The Journal of Gambling Studies and Journal of Gambling Behavior - has shown that gambling, or specifically gamblers, is typically examined under the lens of behavioral science, which is geared towards the psychological identification of excessive gambling. Works done by scholars with an explicit interest in cultural analysis (e.g., Majamäki \& Pöysti, 2012; McMillen, 1996; Raento \& Schwartz, 2011; Reith, 1999) tend to revolve around gambling as a cultural phenomenon or along the line of historical development.

Surprisingly, there has been a lack of research about gambling among discourse analysts. Discourse, or language in general, is indispensable to gambling. When a gambler places a bet before a horse race, the transaction would not be possible without language. Clear rules on how players should behave are laid down for each casino game; an infringement of the rules could revoke any winnings. Given the importance of language in gambling activities, it is worth carrying out discourse-oriented studies on gambling. I believe that the results of such research will enrich the large quantity of existing scholarly works completed in other disciplines.

An appropriate point of entry for discourse analysts to examine the issue of gambling is to focus on the discursive representation of gamblers as a social group. This strategy is largely informed by the postmodernist view of identity as a 'socially constructed' discursive entity (Benwell \& Stokoe, 2006, p. 17). There are various ways to investigate the discursive representation of gamblers. One of them is to explore how gamblers 'enact' their own identity in naturallyoccurring conversations. This echoes Butler's (1990) notion of 'performativity' in the sense that identity, or 'gender identity' in Butler's discussion, is 'performatively constituted' through discourse (p. 24). Alternatively, attention can be devoted to the institutional construction of gamblers as a social category, viz., the 'institutionally enforced identity' (Bloor \& Bloor, 2007, p. 92). This approach is reminiscent of the Foucauldian line of thought, which has formed the major theoretical root of critical discourse analysis (CDA) (Fairclough, Mulderrig \& Wodak, 2011).

One feature of CDA research is the study of how power is manifested behind discourse. In fact, among discourse analysts there is a sign of emerging interest in the power relations associated with the discursive portrayal of gamblers by social institutions. Two relevant studies have been identified. One of them was conducted by Yoong, Tan and Ng (2013). In their project, news articles about ordinary people winning a huge amount of money from the national lottery 
in Malaysia were examined. The researchers found that the winners are represented as the agents who have 'empowered' themselves and their family in terms of living conditions, thereby making the act of winning appealing (p. 242). Yoong, Tan and Ng (2013, p. 243) claimed that the press sacrifices journalistic integrity by covertly endorsing the pursuit of 'easy money' and promoting the lottery company, which is financially influential in the nation. Contextualized in the neighboring country of Malaysia, the study of Leung and Kong (2013) explored how gamblers' identities are constructed in a Singaporean government campaign against problem gambling. It was reported that a variety of linguistic resources such as process types, evaluative lexis and code choice are used by the state to craft a dichotomy between problematic and non-problematic gamblers. Leung and Kong (2013) argued that such symbolic juxtaposition could be deployed as a means of anchoring citizens' gambling behavior.

The role of social institutions in the discursive portrayal of gamblers will be of central interest to this study because how gamblers are presented by social institutions can have a huge influence on the way gamblers are perceived in society and this may lead to stigmatization. Capitalizing on the aforementioned work of Leung and Kong (2013), the present research will further investigate the institutional discursive representation of gamblers in Singapore. With the abolition of the casino ban in recent years, Singapore is an engaging site of inquiry. In 2005, Prime Minister Lee Hsien Loong (2005) made a nationwide announcement about the decision of the government to legalize casino gambling. Following this announcement, two Integrated Resorts-the Singaporean coinage to denote holiday resorts with amenities that cater for casino-goers-went into operation. The legalization of casino gambling has aroused many public debates. On the one hand, the availability of casinos in Singapore might contribute to a growth in tourism. On the other hand, there is a chance that more social problems are created as a result of gambling addiction.

It has to be borne in mind that numerous institutional voices can be detected with respect to the issue of gambling. The anti-gambling campaign studied by Leung and Kong (2013) mainly conveys the didactic stance adopted by the government. In reality, there are other social institutions that play a role in shaping people's thought. Among these social institutions, I have chosen the press as the source of data to examine the discursive representation of gamblers in the current research. The data will be analyzed via a joint approach of corpus linguistics and CDA. Specifically, there are two main objectives of my study. First, through techniques from corpus linguistics, it aims to unfold how gamblers' identities are discursively constructed in the Singaporean press. Second, it explores how results obtained from corpus linguistics offer a useful means to dissect the complex relationship between discourse, ideology and power. The present research is significant in the sense that it opens up a new direction for gambling-related research in academia. It also informs us of journalistic practices in Singapore regarding the theme of gambling, thus contributing to the field of English for specific purposes.

Prior to the discussion of the theoretical background for the research, it is necessary to clarify the choice of newspaper articles as the genre under investigation.

From the sociological perspective, news is a form of culture (Schudson, 1995). There exists an intimate relationship between news and ideology as the former is potentially a 'social force' (p. 3). As Schudson (1995) explained, news is created by certain members of the society who control, 'within a cultural system, a reservoir of stored cultural meanings and patterns of discourse' (p. 14). By manipulating such cultural and discursive resources, news producers can attain 'priming' effects in society. A number of concrete examples in daily life were cited by Schudson (1995). For instance, there was a visible increase in cancer screenings among the public after the news that an important national figure had undergone cancer surgery; people who learnt about a recent overseas natural disaster might alter their travel plans (p. 19). Based on what Schudson (1995) stated, the power of news can never be underestimated.

\section{Theoretical Background}

\subsection{Corpus Approach to Discourse}

Corpus approach to discourse generally means the use of computer-assisted tools to study a large body of authentic language data (Partington \& Marchi, 2015). Researchers adopting such an approach are called corpus linguists and they tend to perceive their research data in the form of 'machine-readable corpora' while engaging in language analysis. Corpus linguistics emerged as early as in the 1960s when there was a growing concern about the generative grammar paradigm of relying on the linguists' own 'reflective' or 'introspective' examples to elucidate language use. Nevertheless, corpus linguistics only started to flourish and gain wider acceptance in the 1990s- the period where the world was witnessing advances and popularization in computer technology and computers could be used to process a large amount of running text within a short period of time. Since then, there has been a discernible increase in the application of corpora in linguistic inquiries (Hickey, 2003, pp. 1-3; Teubert \& Cermakova, 2007, pp. 50-51).

Corpus linguistics has a strong empirical evidence-based flavor as it aims at seeking 'attested patterns' of language practice based on larger vaults of discourse (Mautner, 2016, p. 170). One central belief shared among corpus linguists is that corpus methods allow them to make discoveries and generalizations about characteristics of language use that are hard to detect through researchers' intuition. Hence, the 'researcher bias' can be reduced (Baker, 2006, p. 10).

One may wonder how corpus linguistics can be suitably positioned within the present investigation of discursive portrayal of gamblers in newspaper texts. As Baker (2006, p. 13) opined, corpus linguistics-owing to its patternseeking character on the basis of a large collection of text-is good at revealing the 'incremental effect of discourse.' By compiling a corpus of newspaper texts on gamblers over an extended period of time and subsequently carrying out 
proper linguistic inquiries on the corpus, this study will be able to offer evidence on how the media incrementally present and circulate a salient set of gamblers' images, thereby achieving what Gramsci (1971) called 'cultural hegemony.'

\subsection{The 'Synergy' of Corpus Linguistics and CDA}

CDA is a research program which focuses on disclosing power relations and ideology through the analysis of discourse. Relevant notable works include Fairclough (2003, 2015), van Dijk (2008) and van Leeuwen (2008). However, critical discourse analysts have been criticized for their 'problem of objectivity' as it is said that they have the tendency to choose small data sets which may not result in generalizable analysis. To circumvent the shortcoming of CDA, scholars have proposed to increase its methodological thoroughness by incorporating tools developed by corpus linguists (Cheng, 2013, p. 1353). As Baker et al. (2008, p. 297) remarked, CDA can be enriched by including more objective and quantitative techniques from corpus linguistics as quantification can show the level of generality or trustworthiness with respect to the research findings and conclusions, hence protecting itself against 'over- or under-interpretation.'

The integration of corpus linguistics into discourse research is evident in scholarly studies undertaken in recent years. In the rest of this section, a brief review of the relevant studies will be given.

It is noticed that apart from the joint focus on news discourse, all the studies (Baker et al., 2008; Brindle, 2016; CaldasCoulthard \& Moon, 2010; Cheng \& Lam, 2010; Jaworska \& Krishnamurthy, 2012; O'Halloran, 2007; Orpin, 2005) share two commonalities. First, the initial stage of the analysis is always pertinent to the quantitative processing of the data vis-à-vis the lexico-grammatical and/or the collocational aspects (e.g., the 'co-selection of words') of the texts. This would then be followed by close qualitative examination/interpretation of the concordance lines concerning specific language items. Second, like what Caldas-Coulthard and Moon (2010) said, the studies aim at unraveling the 'ideological implications' of the language choices of the media. Specifically, they carry the intention of illuminating how certain social groups or issues are categorized by the press. Examples include refugees and asylum seekers (Baker et al., 2008), men and women (Caldas-Coulthard \& Moon, 2010; Jaworska \& Krishnamurthy, 2012), protesters (Brindle, 2016), human rights (Cheng \& Lam, 2010) and bribery (Orpin, 2005). All the studies capitalize on corpus-based techniques to derive empirical evidence on the ideological positions taken and transmitted by the media, which might not be recognizable among the 'non-critical' target audience.

For example, Baker et al. (2008) investigated a corpus of British newspaper texts regarding the discursive portrayal of refugees, asylum seekers, immigrants and migrants (altogether referred to as 'RASIM') over a span of ten years (viz., from 1996 to 2005). The corpus consists of 140 million words. The collocational analysis shows that although immigration is supposed to be a process that involves careful planning, the terms 'immigrants' and 'migrants' tend to be co-selected with 'fled' and 'fleeing.' Also, 20 percent of the references to refugees and asylum seekers are represented via quantification in association with metaphors related to water such as 'pour,' 'stream' and 'flood.' The researchers argued that this is a tactic adopted by the press to 'dehumanize' the social groups of refugees and asylum seekers, presenting them as an 'out-of-control, agentless, unwanted natural disaster' (p. 287).

On the other hand, Orpin (2005) presented her analysis of the collocational patterns regarding the term 'corruption' and its synonyms such as 'bribery,' 'sleaze,' 'impropriety,' 'malpractice,' 'cronyism,' 'graft' and 'nepotism' in British newspapers. One interesting pattern identified is that words with more salient negative associations like 'corruption' and 'bribery' are the preferred lexical options when the texts refer to events overseas (viz., countries such as Italy, Pakistan, Malaysia, India, etc.) whereas this is not the case for reports of similar activities that happened within the British border (p. 58). Orpin (2005) believed that corpus-related tools can facilitate the disclosure of the 'ideological stance' held by the British press.

It is not feasible to provide a voluminous account of all the relevant studies. What has been reflected in the literature review here is that a corpus-based linguistic approach to analyzing newspaper texts is well-established in the realm of CDA. This can be considered a forceful justification for the utilization of corpus-oriented techniques in the present research.

\section{Method}

\subsection{Corpus Building}

To research the media portrayal of gamblers in the Singapore press, a corpus of articles which had been released between 17 April 2005 and 28 April 2013 in the leading English language local newspaper The Straits Times was compiled. On 18 April 2005, the public was informed of the government's intention to remove the ban on casinos (Lee, 2005). Since the announcement was made, there have been numerous discussions in society regarding the social implications of the government's decision (e.g., the predicted surge in gamblers). As mentioned earlier, this study is interested in the prevailing 'incremental effect of discourse' (Baker, 2006, p. 13). A broad time frame for the inclusion of articles would therefore be needed. The Straits Times was chosen mainly due to two reasons. First, launched on 15 July 1845, it has become an established Singaporean newspapers (Singapore Press Holdings Ltd., 2016). Second, with an average net circulation of 308605 per issue between January and December 2014, The Straits Times is widely read in Singapore (Audit Bureau of Circulations Singapore Pte. Ltd., 2016).

The news articles were first retrieved from LexisNexis with the search request 'Singapore AND gambler(s).' It was 
discovered that among the 896 hits generated, seven texts appeared twice. The repeated occurrence of these seven texts was subsequently discarded. Hence, eventually, the corpus compiled contains 889 articles, amounting to 615827 running words.

The corpus contains various kinds of newspaper articles, such as reports, feature stories and editorials. A remark has to be made vis-à-vis the reason for not focusing on one news material in the present research. There is no doubt that news can differ by nature. One agreed-upon observation is the division between hard news and soft news mentioned by Bell (1991, pp. 14-15). Despite such differentiation, solely concentrating on one type of newspaper texts and excluding the rest will not generate comprehensive findings for this study as it aims at delving into how gamblers are discursively portrayed by the Singapore press as a collective form of mass media. Also, the rigid demarcation between different types of newspaper texts may seem artificial as the reality can be much more complicated. For instance, extensive 'box stories' may be found in news reports while editorials may carry detailed descriptions of recent accidents. As Meinhof and Smith (2000) advocated, texts produced by the media bear numerous traces of other texts of dissimilar types so they can barely be perceived as a 'static entity' (p. 12). The umbrella term 'reportage' is sometimes used to denote all news irrespective of its characteristics (Bell, 1991, p. 15).

The corpus compiled for the present research is valid and reliable. First, the articles collected come from the newspaper with the highest national standing in Singapore. The credibility of the data source is guaranteed. Second, the data cover a sufficiently large time frame and include a wide range of text types. The size of the corpus is thus large enough to yield valid findings.

The software program which was used for analysis is WordSmith Tools 6.0 (Scott, 2012). WordSmith Tools is useful for quantitative analysis because it can generate frequency lists, perform concordance queries, compute collocations for specific words, look for 'keywords' in a text/corpus and display their distribution (Baker, Hardie \& McEnery, 2006, pp. 169-170). In the present research, collocation is the focus of analysis.

\subsection{Collocation}

As stated by Xiao (2015, pp. 106-107), collocation broadly refers to the extent of word associations (viz., the tendency of a word to appear in the neighborhood of another word). There are a few statistical methods for collocation analysis. Among them, the popular ones are the 't-score' and the 'mutual information' value. The 't-score' and the 'mutual information' value are obtained by means of different equations. While the 't-score' is more likely to include function words, the 'mutual information' value tends to single out lexical collocates (Cheng, 2012, pp. 94-95). As a convention, statistical significance is attained if the 't-score' result is at least 2.576 or the 'mutual information' value reaches 3.0 (Xiao, 2015, pp. 109-110). In the present research, the 'mutual information' value was adopted because in comparison with function words, lexical words are more able to vividly and explicitly contribute to the discursive representation of gamblers.

\subsection{Qualitative Analysis of Concordance Lines}

Corpus analysis is not just about presenting the mechanical outputs produced by the software. Instead, qualitative examination of the outputs is indispensable to a comprehensive corpus-related study. This typically means thorough manual checks on the concordance lines to find out the usual environment in which the lexical items concerned appear (Mautner, 2016; Orpin, 2005). This type of qualitative investigation on the concordance lines can be systematized by using the notions of 'semantic prosody' and 'semantic preference' (Sinclair, 2004, pp. 32-34).

As defined by Sinclair (2003), the word 'prosody' in 'semantic prosody' is borrowed from the field of phonology. Prosody refers to a meaning-bearing event which does not have to be situated in a specific unit of expression, but may stretch across several units (p. 178). Sinclair (2003) maintained that semantic prosody is usually determined via evidence from corpora, i.e., confirmation obtained by examining relevant concordance lines. It is thought that words group together to create unique meanings and such grouping can barely be elucidated through dictionary-like definitions per se. Semantic prosody is a label employed to represent this kind of special meanings. In simpler terms, semantic prosody is reminiscent of 'connotation' (p. 178).

Intimately related to semantic prosody is the notion of 'semantic preference.' It is difficult to set up a neat boundary between the two notions as Sinclair (2004, p. 35) himself also acknowledged that on some occasions, the semantic prosody and the semantic preference are blended. According to Baker, Hardie and McEnery (2006, pp. 144-145), one useful way to differentiate between the two is the presence (or absence) of the speakers' attitudes. Semantic preference captures meanings which are independent of speakers whereas semantic prosody entails the expression of attitudes. Usually semantic preference involves certain categorization or 'semantic fields.' For instance, some collocates of the word 'cup' in the British National Corpus are 'coffee,' 'coca-cola' and 'tea.' This means that the word 'cup' carries a semantic preference for 'drinks' (Baker \& Ellece, 2011, pp. 125-126).

\section{Findings and Discussion}

Table 1 shows the top fifty collocates of 'gambler*' (including the nodes gambler, gamblers, gambler's and gamblers') within the corpus. Before any in-depth analysis is presented, it is vital to specify the steps taken in order to derive the figures shown in Table 1 as different 'collocate settings' could produce different results (Scott, 2013, pp. 155-156). 
Table 1. First 50 collocates of 'gambler*' based on 'mutual information'

\begin{tabular}{|c|c|c|c|c|}
\hline Rank & Collocate & Corpus frequency & Joint frequency & Significance \\
\hline 1 & gambler's & 49 & $\wedge 52$ & 13.72 \\
\hline 2 & banned & 93 & 11 & 10.56 \\
\hline 3 & gambler & 501 & $\wedge 508$ & 10.30 \\
\hline 4 & inveterate & 10 & 10 & 10.28 \\
\hline 5 & pathological & 81 & 65 & 9.97 \\
\hline 6 & habitual & 17 & 12 & 9.78 \\
\hline 7 & compulsive & 86 & 59 & 9.74 \\
\hline 8 & family & 856 & 56 & 9.70 \\
\hline 9 & Kaiji & 17 & 11 & 9.66 \\
\hline 10 & chronic & 22 & 12 & 9.41 \\
\hline 11 & wife & 207 & 11 & 9.40 \\
\hline 12 & out & 1369 & 53 & 8.95 \\
\hline 13 & gamblers & 1404 & $\wedge 1450$ & 8.84 \\
\hline 14 & heavy & 68 & 23 & 8.72 \\
\hline 15 & long & 394 & 13 & 8.72 \\
\hline 16 & say & 426 & 14 & 8.71 \\
\hline 17 & identify & 39 & 11 & 8.46 \\
\hline 18 & even & 723 & 18 & 8.31 \\
\hline 19 & frequent & 62 & 39 & 8.13 \\
\hline 20 & hardcore & 25 & 15 & 8.06 \\
\hline 21 & professional & 66 & 13 & 7.94 \\
\hline 22 & suicide & 70 & 13 & 7.86 \\
\hline 23 & we & 1466 & 26 & 7.82 \\
\hline 24 & he & 5269 & 92 & 7.80 \\
\hline 25 & spot & 61 & 10 & 7.68 \\
\hline 26 & help & 836 & 122 & 7.52 \\
\hline 27 & rolling & 40 & 16 & 7.48 \\
\hline 28 & Mrs & 86 & 12 & 7.44 \\
\hline 29 & God & 52 & 19 & 7.35 \\
\hline 30 & problem & 1081 & 367 & 7.24 \\
\hline 31 & visits & 104 & 11 & 7.04 \\
\hline 32 & deter & 50 & 14 & 6.96 \\
\hline 33 & often & 207 & 20 & 6.91 \\
\hline 34 & seeking & 108 & 29 & 6.90 \\
\hline 35 & stop & 211 & 20 & 6.89 \\
\hline 36 & debt & 216 & 20 & 6.85 \\
\hline 37 & losing & 120 & 11 & 6.84 \\
\hline 38 & fellow & 48 & 11 & 6.67 \\
\hline 39 & desperate & 53 & 12 & 6.65 \\
\hline 40 & who & 2798 & 225 & 6.65 \\
\hline 41 & husband & 151 & 12 & 6.63 \\
\hline 42 & hope & 206 & 16 & 6.60 \\
\hline 43 & addicted & 74 & 16 & 6.59 \\
\hline 44 & amounts & 48 & 10 & 6.53 \\
\hline 45 & seek & 141 & 29 & 6.52 \\
\hline 46 & families & 327 & 66 & 6.49 \\
\hline 47 & himself & 140 & 10 & 6.48 \\
\hline 48 & Chia & 141 & 10 & 6.47 \\
\hline 49 & high & 523 & 36 & 6.42 \\
\hline 50 & their & 2659 & 178 & 6.38 \\
\hline
\end{tabular}

First, the 'collocation span' was set at N-5, N+5. The collocation span, also known as the 'collocate horizons' by Scott (2013, p. 152), represents the number of words to either side of the node word which would be included in the collocation analysis. The default value adopted by WordSmith Tools is N-5, N+5 (Scott, 2013, p. 152). This is one of the reasons why the 'collocate horizons' in the present research follow this value. The other reason concerns an unofficial routine. As Sinclair (2004, p. 198) pointed out, there are always controversies surrounding the best possible size of the collocation span. However, a distance of five words to the left and right is generally the measure accepted in practice (p. 141).

Second, 'mutual information' was used for analyzing collocational strength. There is one major criticism regarding the 
use of 'mutual information.' According to Cheng (2012, p. 95), the collocation list obtained through 'mutual information' is prone to pick up collocates that are rare occurrences with the node, hence making the subsequent analysis less illuminating. To address this issue, the recommendation given by Scott (2013, p. 158) was adhered to. In order to be considered for collocation analysis, the words in question (i.e., the prospective collocates) must have emerged within the vicinity of the node at least 10 times. In other words, if the joint frequency is less than 10 , the words would be automatically excluded from the collocation list.

Third, 'self-collocation' was left out in the analysis. As Sinclair, Jones and Daley (2004, p. 83) opined, it is likely for those node words with high frequency to become collocates of themselves. They claimed that 'self-collocation' is a common phenomenon and is not anything special (p. 84). 'Self-collocation' also clarifies the irregularities identified in Table 1 above. As indicated by the caret symbol ^, the collocates gambler's, gambler and gamblers - which are all cases of 'self-collocation' - display a joint frequency higher than their individual frequency in the corpus. The explanation for this is that the joint frequency is inflated by those instances where the node word and the 'collocate' coincide in the same position of the concordance line. Due to such distortion, a decision was made to remove 'self-collocation' from the analysis.

As Baker (2006, p. 120) suggested, in order to conduct collocation analysis systematically, researchers are advised to explore the possibility of sorting the collocates 'semantically, thematically or grammatically' after the list of the strongest collocates is generated. Grouping related collocates together can provide researchers with a basis for analyzing the words in an orderly manner. After a preliminary review of the findings shown in Table 1, it was decided that the 47 collocates (with the exclusion of the three cases of 'self-collocation') would be grouped grammatically for subsequent analysis. The reason for grouping the collocates grammatically is that parts of speech (viz., grammatical labels such as 'nouns,' 'verbs' and 'adjectives') constitute a more objective treatment vis-à-vis the collocates. Once the collocates are appropriately sorted into grammatical categories, analysis geared towards the semantic and/or thematic lenses can be carried out. In fact, this approach of collocation analysis has been adopted by some prior researchers (e.g., Baker, Gabrielatos \& McEnery, 2013b).

Table 2 captures the collocates of 'gambler*' which have been grouped grammatically. It is noted from Table 2 that most of the collocates are content words, i.e., verbs, adjectives, nouns and adverbs. This should not be surprising, given the selection of 'mutual information' to analyze word associations in the present study (Baker, 2006, p. 102). The words printed in bold ('frequent,' 'spot,' 'help,' 'hope' and 'out') are placed across two categories since the concordance analysis shows that their use with respect to the node 'gambler*' in the newspaper texts is grammatically more diverse, probably due to the 'polysemous nature' of these words.

Table 2. Grammatical categories of the collocates of 'gambler*'

\begin{tabular}{lllllll}
\hline Verb & Adjective & Noun & Adverb & Preposition & Pronoun & Determiner \\
\hline banned & inveterate & family & out & out & we & their \\
\hline say & pathological & Kaiji & even & & he & who \\
\hline identify & habitual & wife & often & & himself \\
\hline frequent & compulsive & suicide & & & \\
\hline spot & chronic & spot & help & & \\
\hline help & heavy & Mrs & & \\
\hline deter & long & God & & \\
\hline seeking & frequent & problem & & \\
\hline stop & hardcore & visits & & \\
\hline losing & professional & debt & & \\
\hline hope & rolling & husband & & \\
\hline seek & fellow & hesperate & hope & amounts & \\
\hline \multicolumn{7}{c}{ families } \\
\hline
\end{tabular}

For instance, as Figure 1 displays, the collocate 'frequent' is used as an attributive adjective modifying the noun 'gambler(s)' most of the time; however there is one case where it is used as a verb in the relative clause that concerns the gamblers' action of 'frequenting' Long Jie, a cruise ship with gambling facilities (Wikipedia, 2015). In a similar vein, Figure 2 reveals the even distribution of the two different grammatical manifestations of the collocate 'help.' While those instances of 'help' which are found to the right of the node tend to be nouns representing the assistance actively sought by the gamblers, those to the left of the node are usually verbs which portray the gamblers as the passive parties who are acted upon by others. 
1 clientele remained, it is now 50 per cent.

2 to the casinos. This assumes that frequent

3 impact such safeguards can make. Frequent

4 also Vietnamese businessmen and frequent

5 casinos. This will definitely help frequent

6 the fairness of restricting visits by frequent

7 He estimated the number of such frequent

8 address the root of the problem, as frequent

9 by Ms Nakayama because he was a frequent
'Gamblers who frequent Long Jie now come to gamblers are problem gamblers, but this may not gamblers are few, in the first place. Annual entry gamblers here. Khoi, who sells properties, clothes gamblers to overcome their addiction. Casino gamblers who have paid the annual entry levy of gamblers to be 4,000 to 6,000 . In assessing an gamblers still get the chance to gamble away gambler at Marina Bay Sands. It was also pointed

Figure 1. Sample concordance of 'gambler*' when it co-occurs with 'frequent'

dropout rate? The main reason is that many
2 psychological, for them to consider. If the
3
at two agencies. The number of problem
and this has made it no longer taboo for
5
6 not seen a spike in the number of elderly
7 Christian outfits, they saw the need to help
8 Pagar FSC, said counselling will also help a
9 centres around Singapore to help habitual
to recognise and help potential problem

Figure 2. Sample concordance of 'gambler*' when it co-occurs with 'help'

The three underlined collocates ('Kaiji,' 'God' and 'Chia') are proper nouns. The first two are words found in the title of two movies-Kaiji: The Ultimate Gambler and God of Gamblers. 'Chia' is the surname of a Singaporean inveterate gambler whose commercial frauds have been widely reported. Two examples are given below:

(1) A high-stakes legal battle opens today, when the High Court will hear how convicted high-rolling gambler Chia Teck Leng hoodwinked four foreign banks of \$73US million (\$109S million), between 1999 and 2003, to fund his habit. (1 October 2007)

(2) A judge is to decide how more than $\$ 40$ million in cash, property and jewellery linked to convicted high-rolling gambler Chia Teck Leng is to be distributed. (14 August 2006)

Although proper nouns are likely to be discounted in collocation analysis (Baker, 2006, p. 109), two meaningful remarks can be made here. First, it can be inferred from the two collocates 'Kaiji' and 'God' that the images of gamblers are popularized through other cultural products such as films. Second, references to Chia Teck Leng constantly happen in news stories about his deceptive behavior caused by gambling addiction and the severe penalty meted out to him. This is reminiscent of van Leeuwen's (2008, pp. 116-118) idea of 'cautionary tales'-narratives in which deviant behavior eventually leads to punishment. Here, 'cautionary tales' are strategically employed by the press to make pathological gambling illegitimate.

4.1 A Seeker-Cum-Loser that Has to be Restrained

The verb collocates identified for 'gambler*' construct the population of gamblers as a group of seekers and losers that have to be detected, assisted or even curbed. Such negative 'semantic prosody' surrounding 'gamblers' can be verified by examining the concordance lines which contain the collocates 'banned' (10 cases), 'identify' (11), 'spot' (8), 'help' (33), 'deter' (14), 'seeking' (29), 'stop' (12), 'losing' (11) and 'seek' (23). Figure 3 offers an exemplification of such cases.

cases of voluntary self-exclusion, where the problem, to identify and help problem in July to train staff to spot and help problem topical are groups emerging to help problem reasonable to expect casinos to actively deter centres report an increase in the number of can then be set to exclude or stop problem following a spate of news reports on local and this has made it no longer taboo for He said: 'To help us cope with the increase in patrol the gaming floor to identify problem

The Government may not be able to stop New code may ask operators to spot problem gamblers get themselves banned from casinos with gamblers and especially their families. MCYS has gamblers. 'I am sure it's very important to Singapore gamblers. At least four organisations have started gamblers. They are more likely to do the opposite. gamblers seeking help for addiction in the past year, gambler, or slow down the rate of play when they gamblers losing staggering amounts and the rising gamblers to seek help.' The service centre has received gamblers seeking counselling, we plan to invite gamblers, or set up a booth on site where gamblers can gamblers from trying their luck at the casinos but there gamblers; Council wants help from industry players to

Figure 3. Sample concordance portraying gamblers as a seeker-cum-loser that has to be restrained 
An interesting pattern stems from the two collocates 'seeking' and 'seek.' While gamblers are clinically defined by psychiatrists as individuals who 'are seeking "action" (an aroused, euphoric state) or excitement' (American Psychiatric Association, 2000, p. 671), the 'seeker' image invoked in the newspaper texts is largely related to the gamblers' search for corrective assistance, medical treatment and therapy. Only two instances call upon the gamblers' predisposition to ecstasy. This can be illustrated by Lines 1 and 12 in Figure 4 below.

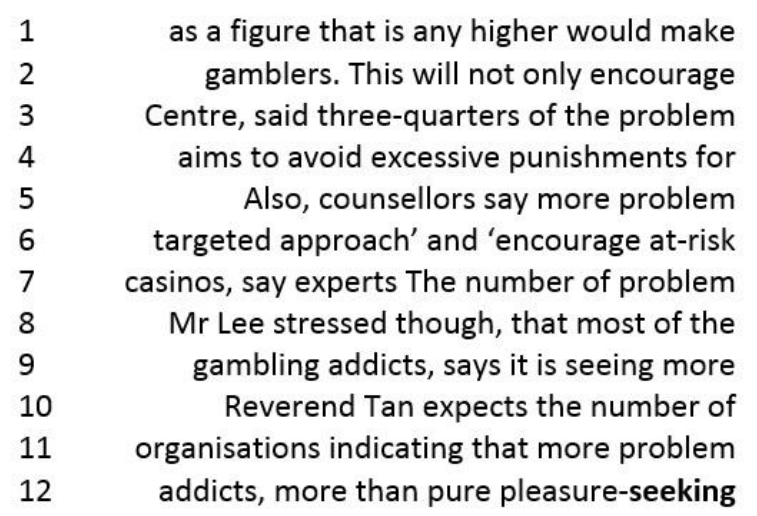

gamblers seek their thrills abroad. At the same time, gamblers to seek counselling but also benefit the banks gamblers who seek help come with problems related to gamblers who are trying to seek help. The High Court gamblers have come forward to seek help. Still, the IRs gamblers and their families to seek help'. Mr Charles gamblers seeking medical treatment and counselling gamblers seeking help 'have a history that predates the gamblers seeking help. Its latest figures, which are for gamblers seeking help to continue to rise. He said: 'To gamblers have been seeking help since the casinos gamblers, are more likely to have other substance

Figure 4. Sample concordance of 'gambler*' when it co-occurs with 'seeking' or 'seek'

Another noteworthy pattern concerns the collocate 'say.' Examination of the concordance lines reveals that surprisingly, when 'say' is used in the neighborhood of 'gambler*,' the 'sayer' of this verbal process is hardly ever the gambler(s). As Figure 5 exhibits, gamblers are predominantly the ones subject to comments or analytical statements made by various other people including business analysts, counseling experts and legal professionals. The only exception is Line 3. Nevertheless, even for this case, the gamblers' speech is very delicately framed within the remark made by counseling organizations. Obviously, the gamblers' voice is subdued, and such suppression of voice not only echoes, but also intensifies the societal control exerted on gamblers as reflected by the aforementioned collocates 'banned, 'identify,' 'spot,' 'deter' and 'stop.' By using van Leeuwen's (2008, p. 52) terminology, it can be argued that when the gamblers are represented through 'genericization,' their collective voice is inhibited

welfare organisations offering counselling to plans as Macau attracts the more serious Counselling centres say about seven in 10 of the in search of another table. More problem have been hit, but junket operators who take as demand for easy loans exists. Counsellors say Also, counsellors say more problem their money back. Lawyers say the ruling puts

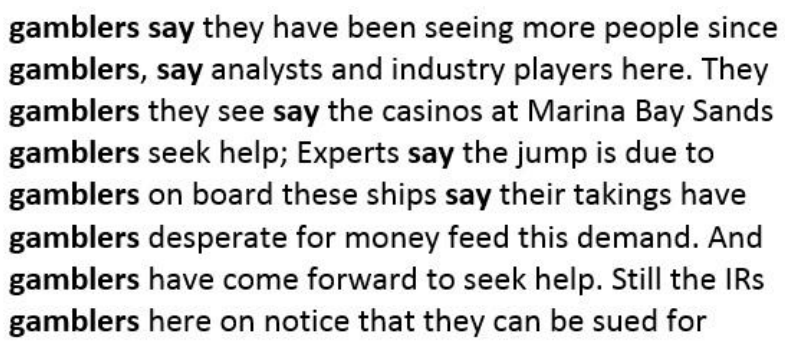

gamblers say they have been seeing more people since gamblers, say analysts and industry players here. They gamblers they see say the casinos at Marina Bay Sands gamblers seek help; Experts say the jump is due to gamblers on board these ships say their takings have gamblers have come forward to seek help. Still the IRs gamblers here on notice that they can be sued for

Figure 5. Sample concordance of 'gambler*' when it co-occurs with 'say'

Findings concerning how gamblers' identities are constructed via the use of specific verbs were also presented by Leung and Kong (2013), who investigated four gamblers' monologues taken from a governmental website against excessive gambling. It was found that action verbs are used to construct the identity of problematic gamblers as one which is full of personal dramas (e.g., 'end my life' and 'beat me up'). Also, verbal processes such as 'say' and 'warn' signify gamblers' interactions with their family and friends, thereby highlighting their interpersonal identity (pp. 36-37). The findings of Leung and Kong (2013) are in stark contrast to the gamblers' images revealed in the present research.

\subsection{The Embodiment of Fixations}

Apart from being cast as the parties that need external monitoring, gamblers are characterized as lacking the internal ability of self-control, resulting in behavioral fixations. Under the realm of psychoanalysis, 'fixation' is a term developed by Sigmund Freud, the notable pioneer of the field, to describe how a 'permanent disorder' is formed via obsession with gratifying stimulations from the social environment (Freud, 1962, pp. 108-109). The Freudian sense of 'fixation' is in fact consistently activated within the present corpus of newspaper texts about gamblers through the adjective collocates 'inveterate,' 'pathological,' 'habitual,' 'compulsive,' 'chronic,' 'heavy,' 'frequent,' 'hardcore,' 'addicted' and also 'high-rolling' - the contiguous occurrence of the two identified adjective collocates 'high' and 'rolling.' Most of these collocates suggest a negative 'semantic prosody.' For instance, the adjective 'chronic' is usually used for undesirable matters, such as diseases, pain and illness. On the other hand, something that is 'heavy' is prone to disapproval (e.g., 'heavy rain,' 'heavy traffic' and 'heavy workload'). Figure 6 shows a sample of the adjective collocates of 'gambler*.' 
1 encourage gambling in a country of inveterate 2 opening of a casino as problem and pathological 3 about gambling.' He admitted being a habitual 4 offence. Later that month, the compulsive 5 trained to provide counseling to chronic 6 end up like him.' Also, his own father, a heavy 7 trigger curbs; checks will be run on frequent 8 But we need such hard measures, as hardcore 9 revenue comes from problem or addicted 10 and junket operators who introduce high-rolling gamblers. Opinion polls show he has public backing. gamblers begin to deplete their resources. Gamblers gamblers, playing cards, betting on soccer, playing 4-D gambler was caught gaming again at a void deck in gamblers. Many families have split up due to a chronic gambler who quit two years ago to keep the family gamblers to find out if they are in financial distress gamblers need to be 'slapped' with hard data in order gamblers,' he said. 'These are dangerous machines, gamblers to casinos. Education Ministry projects

Figure 6. Sample concordance portraying gamblers as the embodiment of fixations

Two observations about the adjective collocates can be made. First, the adjectives are mostly located immediately to the left of the node 'gambler*.' It can be argued that without any intervening word in the middle, such lexical contiguity makes the gamblers' 'fixations' more discursively explicit and easily detectable, thereby foregrounding and exacerbating the associated negativity. Second, with reference to Martin and White's (2005, p. 52) appraisal theory, most of the adjective collocates are orientated towards the 'normality' facet of 'social esteem judgment' markers, as these collocates jointly construe the gamblers' eccentricity.

An additional negative meaning is attributed to the gamblers' abnormality through the overtly emotive adjective collocate 'desperate.' In Martin and White's taxonomy, 'desperate' can be regarded as an 'affect' marker (2005, p. 45). Investigation of the concordance lines (Figure 7) demonstrates that all the instances of collocation with respect to 'desperate' and 'gambler*' involve the construal of the gamblers' distress.

1 demand for easy loans exists. Counsellors say

2 off debts. Counsellors also speak of problem 3 and suicide experts who feel that while the 4 a grave misconception to believe that 'while the 5 mend their family relationships. Most of the 6 of control as losses become unmanageable. The 7 very impulsiveness that can cause a desperate 8 tries to do so. But that does not stop desperate 9 drop down a lush cliff-face. Tri says desperate 10 Poh Choo Hwee knows how desperate hardcore 11 every day. 'Those who're desperate-especially gamblers desperate for money feed this demand. And gamblers desperate for money to bet further to recoup gamblers may sound desperate, they actually pose a gambler may sound desperate they actually pose a low gamblers we see are hopeless, desperate and suicidal. gambler feels powerless, remorseful and desperate. gambler to kill himself. 'Almost all gamblers act on gamblers like Johnny. Recalling his long and troubled gamblers used to jump off there, and the Khmer Rouge gamblers can be. Her grandmother ran an illegal gamblers-won't quibble too much about the offer. gambler to win back his money at the tables. He

Figure 7. Sample concordance of 'gambler*' when it co-occurs with 'desperate'

Using adjectives with a particular semantic load to depict a social group is one common strategy in media discourse. An example is the representation of Muslims in British newspaper articles as shown in the study of Baker, Gabrielatos and McEnery (2013a). The researchers noted that adjectives denoting 'strong belief' like 'pious,' 'strict' and 'devout' tend to modify the noun 'Muslim' (p. 39). The present research has demonstrated once again that adjectives are important linguistic devices in the explicit construal of social groups.

\subsection{Familial Burdens, Male Villains and Female Victims}

The noun collocates are more diverse in terms of their semantic make-up. Nonetheless, there appears to be a 'semantic preference' for familial relationships, as evidenced by the collocates 'family, 'wife,' 'husband' and 'families.'

The collocates 'family' and 'families' have a preponderance of being associated with 'gambler*' via (i) a possessive determiner; (ii) a prepositional phrase with 'of' (i.e., a qualifier); (iii) the conjunction 'and.' Some examples are presented in Figure 8 below.

free counselling and treatment for problem announced that it would launch a new hotline for o enhance counselling and treatment for problem collaborate to provide assistance to problem financial relief to families of problem is now available for the families of problem agrees. Before anyone is banned, both the

On one hand we have to help compulsive asking two charities to do more to help problem told that immediate family members of the was only fair that the family members of problem all it takes is for family members and problem gamblers and their families. Still, as the commission gamblers and their families next Saturday. The hotline gamblers and their families. Win big on lottery that is gamblers and their families. The National Council on gamblers and help them meet the administrative costs gamblers-a group often overlooked. The National gambler and his family will be counselled. If the gamblers and their broken, misplaced family members, gamblers and their families. Yesterday, it announced gambler could apply for the exclusion order, and the gamblers had some way to help them refrain from gamblers to inform the Credit Bureau of Singapore of the *' when it co-occurs with 'family' or 'families' 
Whilst an 'association' (van Leeuwen, 2008, pp. 38-39) is woven between gamblers and their family within the news reports, the gamblers' family is typically represented as the affected party who needs outside help, alongside the gamblers. The evidence can be derived from the concordance lines in Figure 8. From time to time, the portrayal of the family members as the receiving end of extra assistance is triggered by the two prepositions 'for' and 'to.' Such a finding was not reported in the study of Leung and Kong (2013).

Moreover, on some occasions (e.g., Lines 10, 11 and 12), the family is even reported as the person liable for the supervision of the gamblers' behavior. This can be partly caused by the fact that family members in Singapore are eligible to exclude their significant others from the two local casinos (Casino Regulatory Authority, 2014). The identities of gamblers as creators of familial burdens or added responsibilities are deliberately brought to the fore.

Gender stereotyping is also embedded within the newspaper texts about gamblers. This can be disambiguated via investigation of the concordance lines containing the noun collocates 'husband' and 'wife.' The concordance observation reveals that 'her' is a highly frequent co-occurring word ( 13 instances). Figure 9 constitutes a sample of the concordance lines with the co-occurrence of 'gambler*,' 'husband' and 'her.' It becomes obvious that when contextualized within a spousal relationship, the gambler tends to be construed as the male partner. This is especially so with the three-word cluster 'her gambler husband' in Lines 1 to 3.

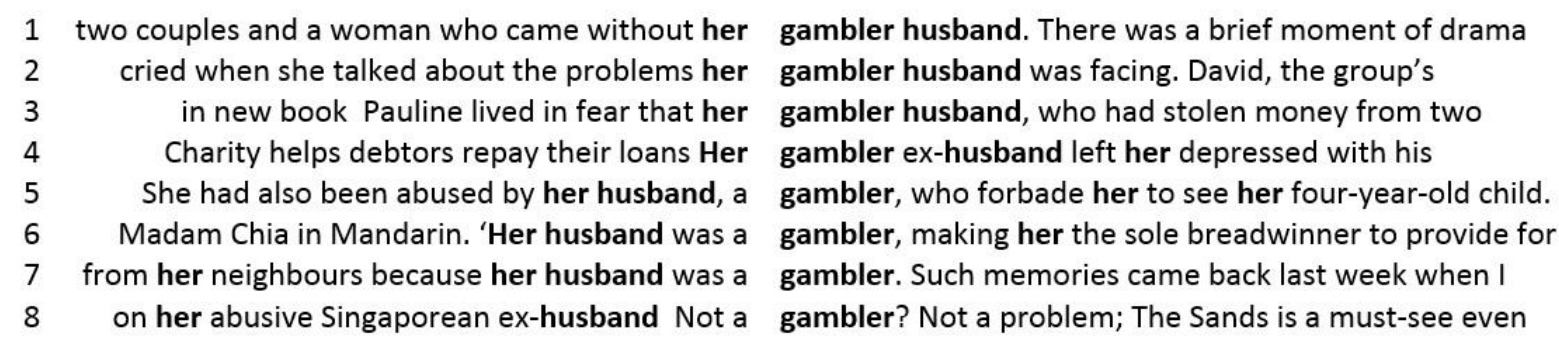

Figure 9. Sample concordance of 'her' when it co-occurs with 'gambler*' and 'husband'

Such gender-skewed representation of gamblers is further exemplified by the strong associations between the word 'gambler*' and the masculine pronoun 'he' as the latter falls into the list of top collocates as well. According to Table 1 above, 'he' ranks 24th, implying a very high level of collocation with 'gambler*.' Subsequent concordance analysis indicates that 'he' is often used as a 'personal reference item' (Halliday \& Matthiessen, 2014, p. 626) to denote a specific gambler in an anaphoric way. Examples are displayed in Figure 10.

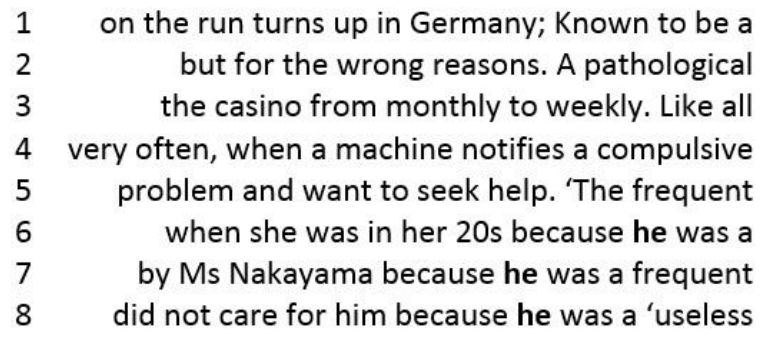

gambler, he allegedly ran off with $\$ 5.6$ million of gambler, he would bet on any soccer match, even gamblers, he wanted to recoup his losses. 'It was also gambler that he only has 10 minutes left, he increases gambler will deny that he has a gambling problem,' said gambler who also physically abused her. She met her gambler at Marina Bay Sands. It was also pointed out gambler'. Whenever Chee went to his home to ask for

Figure 10. Sample concordance of 'gambler*' when it co-occurs with 'he'

While men or husbands are frequently 'demonized' as villainous gamblers, women (as reflected by the concordance lines for the noun collocate 'wife') are antithetically victimized. As Figure 11 presents, there are instances (Lines 1 and 2) where the word 'wife' co-occurs with the genitive form of the noun 'gambler,' suggesting that women are the belongings of the gambling husbands. Also, Line 4 shows that the wife is the 'goal' of the extremely inhuman material process 'had killed.' Physical abuse inflicted on women whose husband is a gambler is additionally highlighted by the noun 'wife-beater' in Line 3. Last but not least, in Line 5, the wife is the one impersonated by her gambling husband who used her national identity card (IC) to gain entry into a local casino so as to dodge the casino ban imposed upon him.

are bankrupt. NCPG notes feedback from available since before the casino opened?' One boys aged 16 to 25 and married to a womaniser, clerk, showed him a newspaper article of a Fined for using wife's IC to enter casino gambler's wife I Refer to the letters by Madam Chia gambler's wife, Mrs Tan (not her real name), applied gambler and wife-beater The Victim; She lived in fear gambler who had killed his wife and their two children, Gambler Leow Peng Liam managed to sneak into Resorts

Figure 11. Sample concordance of 'gambler*' when it co-occurs with 'wife' 
As pointed out by Synnott (2009), there is a societal phenomenon of representing females as victims and males as villains. The patterns identified above appear to indicate that newspaper articles are contributing to the reproduction of this phenomenon, against which Synnott (2009) cautioned because it promotes an imbalanced view of men and women.

\subsection{A Social Outcast}

The study of Leung and Kong (2013) has demonstrated that the discursive construction of gamblers' identities continually requires a seemingly unequivocal and yet artificial differentiation between problematic gamblers and those who are not. Through detailed textual analysis, discourse has been shown to play a pivotal role in actualizing the juxtaposition of the two social groups. This is resonant with Foucault's $(1965,1977)$ macro-reasoning in relation to the emergence of the various kinds of social deviants in the contemporary institutionalized world. The attempt made by the institutions to exercise their power of social alienation is attested in the collocation analysis of the present research as well.

The pursuit of drawing a boundary between deviant gamblers and the rest is manifested by means of the pronoun collocate 'we.' Although the first person plural pronoun can be used to 'collectivize' people into a unified group, it may be mobilized as a weapon to marginalize certain social actors by overtly creating the distinction between 'us' and 'them' (van Leeuwen, 2008, p. 40). As a strong collocate (ranking 23) of 'gambler*,' 'we' is often utilized to both referentially and symbolically signify the non-gamblers' voice that is geared towards the institutional outlook on gambling. A sample of concordance can be found in Figure 12.

1 and mend their family relationships. Most of the

2 loans, and if we can tackle the addiction of our

3 on our clinical experience in treating problem

4 for the first 30 years of my life. My dad was a

5 that there is that 1 to 2 per cent of addictive

6 While the motivation of problem

7 to 613. On the casinos' role in the rise in

8 He said: 'To help us cope with the increase in

9 of the profile of its donors? That we are all

10 addiction medicine department. 'We have seen

11 casinos We are looking at how we should have

12 serious gamblers to enter. We do not want non-

13 an all or nothing issue. We already have problem

14 homes. On one hand we have to help compulsive

15 seem unrealistic. We are talking about hard-core

16 of why we probably have more compulsive gamblers we see are hopeless, desperate and suicidal. gamblers, we may have nipped the problem in the bud. gamblers, we think it is a grave misconception to believe gambler and we had to struggle when we were young. gamblers, and we have to be proactively addressing this gamblers may vary, we found that there are gamblers, Mr Lee said: 'We can't blame the presence of gamblers seeking counselling, we plan to invite overseas gamblers? Please show us some respect. I read with gamblers who have tried to gas themselves in a car or gamblers banned from casinos at the behest of family gamblers to enter the casino and pick up the habit when gamblers today. As a MCYS (Ministry of Community gamblers and their broken, misplaced family members, gamblers who hardly ever go home, or are already too gamblers than Macau. We have to find out what works

Figure 12. Sample concordance of 'gambler*' when it co-occurs with 'we'

Among the 16 concordance lines in Figure 12, 15 of them embrace the voice of the non-gamblers when the first person plural pronoun is used. The only exception is Line 9 . But after tracing the original newspaper text where Line 9 is located, I found that the word 'gamblers' is employed metaphorically in a rhetorical question posed by the writer who expressed her deep reprimand for the National Kidney Foundation advertising strategy of launching a lucky draw in order to elicit public donations. Thus, strictly speaking, Line 9 is irrelevant. As for the rest, close observation reveals that when 'we' and 'gambler*' co-occur, the pronoun may denote a large variety of non-gambling parties, including the government and its representatives, the medical professionals, the gamblers' family and other members of the public who are committed to 'tackling' problems associated with excessive gamblers.

The use of 'we' in the way that excludes the gamblers fortifies the dividing line between them and the others. This conveniently helps to further pigeonhole problem gamblers. In fact, the finding about the co-occurrence of 'we' and 'gambler*' in the present corpus is parallel to the aforementioned pattern concerning the verb collocate 'say.' Both findings show that whenever the collective voice is activated, it always involves the non-gamblers, particularly members of the institutions. The gamblers' collective voice, on the other hand, seems to carry a load of illegitimacy so it has to be weakened or even silenced. Their image as an outcast is undeniably crystallized.

\section{Conclusion}

The present article has investigated Singapore newspaper texts about gamblers by combining corpus linguistics and critical discourse analysis. In order to show the role of the press on the discursive representation of gamblers, 889 articles from The Straits Times (Singapore) were extracted through LexisNexis. The gathered texts constitute a 615827 word corpus. The software program WordSmith Tools 6.0 was used to analyze the collocational patterns of the corpus. The analysis was enriched by examination of the concordance lines.

The current corpus-oriented research generates interesting analytic outcomes vis-à-vis the portrayal of gamblers in Singapore media discourse. For instance, archetypal images of both genders are found in the corpus. When the news texts touch upon the marital status of the social actors, the male partner is always crafted as the gambler whereas his female counterpart becomes the sufferer. This is evidenced by the noun collocates 'husband' and 'wife.' Another major 
analytic outcome obtained from the corpus analysis concerns the omnipresent discursively-manifested demarcation between problematic gamblers and those who are not. It was discovered that in the newspaper texts, problematic gamblers tend to be discursively alienated from the others. The adjective collocates of 'gambler*' (e.g., 'inveterate,' 'pathological' and 'chronic') are largely negative 'social esteem judgment' markers (Martin \& White, 2005) signifying the gamblers' abnormality. The institutional endeavor to single out the gamblers is visible via the verb collocates including 'identify,' 'spot' and 'deter.' The social labeling does not just apply to the gamblers in isolation. The collocation analysis indicates that members of the gamblers' family are characterized as the ones that are obligated to monitor the gamblers' behavior and to receive remedies as well.

The corpus analysis has uncovered the 'hegemonizing' nature of the newspaper articles in which the gamblers are consistently marginalized. One obvious manifestation of such 'cultural hegemony' (Gramsci, 1971) is the suppression of the gamblers' collective voice while the institutional voice is amplified. This could be revealed by looking at the coselection of the words 'gambler(s)' and 'we' where the first person plural pronoun is almost exclusively used to represent members of the institutions who are generalizing about the gamblers. Concordance lines with respect to the verb collocate 'say' indicate that gamblers are usually the ones commented on by various other people. The 'hegemonizing' character of the press as demonstrated through the current study lends support to Althusser's (1984, p. 49) remark regarding 'Ideological State Apparatuses' whose function is to 'hail' or 'interpellate' individuals to behave in a certain way. Perhaps, one may argue that the idea of newspaper texts being an instrument of fostering 'cultural hegemony' or imparting ideology is not new and has been discussed by previous scholars. Nonetheless, what this study has accomplished is the provision of concrete discourse evidence towards the argument via corpus analysis. Unquestionably this is a valuable contribution of the study.

\section{References}

Althusser, L. (1984). Essays on ideology. London: Verso.

American Psychiatric Association. (2000). Diagnostic and statistical manual of mental disorders: DSM-IV-TR (4th ed., text rev.). Washington: American Psychiatric Association.

Audit Bureau of Circulations Singapore Pte. Ltd. (2016). ABC audited publications as of January 2016. [Online] Available: http://abcsingapore.org/reports.html (June 11, 2016)

Baker, P. (2006). Using corpora in discourse analysis. London: Continuum.

Baker, P., \& Ellece, S. (2011). Key terms in discourse analysis. New York: Continuum.

Baker, P., Hardie, A., \& McEnery, T. (2006). A glossary of corpus linguistics. Edinburgh: Edinburgh University Press.

Baker, P., Gabrielatos, C., Khosravinik, M., Krzyzanowski, M., McEnery, T., \& Wodak, R. (2008). A useful methodological synergy? Combining critical discourse analysis and corpus linguistics to examine discourses of refugees and asylum seekers in the UK press. Discourse \& Society, 19(3), 273-306. http://dx.doi.org/10.1177/0957926508088962

Baker, P., Gabrielatos, C., \& McEnery, T. (2013a). Discourse analysis and media attitudes: The representation of Islam in the British press. Cambridge: Cambridge University Press.

Baker, P., Gabrielatos, C., \& McEnery, T. (2013b). Sketching Muslims: A corpus driven analysis of representations around the word 'Muslim' in the British press 1998-2009. Applied Linguistics, 34(3), 255-278. http://dx.doi.org/10.1093/applin/ams048

Bell, A. (1991). The language of news media. Oxford: Blackwell.

Benwell, B., \& Stokoe, E. (2006). Discourse and identity. Edinburgh: Edinburgh University Press.

Bloor, M., \& Bloor, T. (2007). The practice of critical discourse analysis: An introduction. London: Hodder Arnold.

Brindle, A. (2016). A corpus analysis of discursive constructions of the Sunflower Student Movement in the Englishlanguage Taiwanese press. Discourse \& Society, 27(1), 3-19. http://dx.doi.org/10.1177/0957926515605957

Butler, J. (1990). Gender trouble: Feminism and the subversion of identity. New York: Routledge.

Caldas-Coulthard, C., \& Moon, R. (2010). 'Curvy, hunky, kinky': Using corpora as tools for critical analysis. Discourse \& Society, 21(2), 99-133. http://dx.doi.org/10.1177/0957926509353843

Casino Regulatory Authority. (2014). Apply for visit limits and exclusion orders. [Online] Available: http://www.cra.gov.sg/cra/apply-for-visit-limits-and-exclusion-orders.aspx/93 (June 11, 2016)

Cheng, W. (2012). Exploring corpus linguistics: Language in action. London: Routledge.

Cheng, W. (2013). Corpus-based linguistic approaches to critical discourse analysis. In C. Chapelle (Ed.), The encyclopedia of applied linguistics (pp. 1353-1360). Oxford: Blackwell.

Cheng, W., \& Lam, P. (2010). Media discourses in Hong Kong: Change in representation of human rights. Text \& Talk, 30(5), 507-527. http://dx.doi.org/10.1515/text.2010.025

Cosgrave, J. (Ed.). (2006). The sociology of risk and gambling reader. New York: Routledge.

Fairclough, N. (2003). Analyzing discourse: Textual analysis for social research. London: Routledge.

Fairclough, N. (2015). Language and power (3rd ed.). New York: Routledge.

Fairclough, N., Mulderrig, J., \& Wodak, R. (2011). Critical discourse analysis. In T. van Dijk (Ed.), Discourse studies: A multidisciplinary introduction (2nd ed.) (pp. 357-378). London: Sage. 
Foucault, M. (1965). Madness and civilization: A history of insanity in the age of reason (R. Howard, Trans.). New York: Pantheon Books.

Foucault, M. (1977). Discipline and punish: The birth of the prison (A. Sheridan, Trans.). New York: Vintage Books. Freud, S. (1962). Three essays on the theory of sexuality (J. Strachey, Trans.). New York: Basic Books.

Gramsci, A. (1971). Selections from the prison notebooks of Antonio Gramsci (Q. Hoare \& G. Smith, Trans.). New York: International.

Halliday, M., \& Matthiessen, C. (2014). Halliday's introduction to functional grammar (4th ed.). Abingdon: Routledge. Hickey, R. (2003). Corpus presenter: Software for language analysis with a manual and 'A corpus of Irish English'as sample data. Amsterdam: John Benjamins.

Jaworska, S., \& Krishnamurthy, R. (2012). On the F word: A corpus-based analysis of the media representation of feminism in British and German press discourse, 1990-2009. Discourse \& Society, 23(4), 401-431. http://dx.doi.org/10.1177/0957926512441113

Lee, H. (2005, April 18). Proposal to develop Integrated Resorts [Ministerial statement]. [Online] Available: https://www.mti.gov.sg/MTIInsights/Documents/Ministerial\%20Statement\%20-\%20PM\%2018apr05.pdf (June 11, 2016) Leung, R., \& Kong, K. (2013). Juxtaposing identities as a symbolic resource: Social and problem gamblers in Singapore's problem gambling campaign. Text \& Talk, 33(1), 25-51. http://dx.doi.org/10.1515/text-2013-0002

Majamäki, M., \& Pöysti, V. (2012). Vocabularies of gambling justification among Finnish and French players. European Journal of Cultural Studies, 15(4), 496-512. http://dx.doi.org/10.1177/1367549412442210

Martin, J., \& White, P. (2005). The language of evaluation: Appraisal in English. Basingstoke: Palgrave Macmillan.

Mautner, G. (2016). Checks and balances: How corpus linguistics can contribute to CDA. In R. Wodak \& M. Meyer (Eds.), Methods of critical discourse studies (3rd ed.) (pp. 154-179). London: Sage.

McMillen, J. (Ed.). (1996). Gambling cultures: Studies in history and interpretation. London: Routledge.

Meinhof, U., \& Smith, J. (2000). The media and their audience: Intertextuality as paradigm. In U. Meinhof \& J. Smith (Eds.), Intertextuality and the media: From genre to everyday life (pp. 1-17). Manchester: Manchester University Press.

O'Halloran, K. (2007). Critical discourse analysis and the corpus-informed interpretation of metaphor at the register level. Applied Linguistics, 28(1), 1-24. http://dx.doi.org/10.1093/applin/aml046

Orpin, D. (2005). Corpus linguistics and critical discourse analysis: Examining the ideology of sleaze. International Journal of Corpus Linguistics, 10(1), 37-61. http://dx.doi.org/10.1075/ijcl.10.1.03orp

Partington, A, \& Marchi, A. (2015). Using corpora in discourse analysis. In D. Biber \& R. Reppen (Eds.), The Cambridge handbook of English corpus linguistics (pp. 216-234). Cambridge: Cambridge University Press.

Raento, P., \& Schwartz, D. (Eds.). (2011). Gambling, space, and time: Shifting boundaries and cultures. Reno: University of Nevada Press.

Reith, G. (1999). The age of chance: Gambling in western culture. London: Routledge.

Schudson, M. (1995). The power of news. Cambridge: Harvard University Press.

Scott, M. (2012). WordSmith Tools version 6. Liverpool: Lexical Analysis Software.

Scott, M. (2013). WordSmith Tools manual version 6.0. Liverpool: Lexical Analysis Software.

Sinclair, J. (2003). Reading concordances: An introduction. Harlow: Longman.

Sinclair, J. (2004). Trust the text: Language, corpus and discourse. London: Routledge.

Sinclair, J., Jones, S., \& Daley, R. (2004). English collocation studies: The OSTI report. London: Continuum.

Singapore Press Holdings Ltd. (2016). Our business: The Straits Times / The Sunday Times. [Online] Available: http://www.sph.com.sg/our-businesses/newspapers/the-straits-times-the-sunday-times (June 11, 2016)

Stubbs, M., \& Halbe, D. (2013). Corpus linguistics: Overview. In C. Chapelle (Ed.), The encyclopedia of applied linguistics (pp. 1377-1379). Oxford: Blackwell.

Synnott, A. (2009). Re-thinking men: Heroes, villains and victims. Farnham: Ashgate.

Teubert, W., \& Cermakova, A. (2007). Corpus linguistics: A short introduction. London: Continuum.

van Dijk, T. (2008). Discourse and power. Houndmills: Palgrave Macmillan.

van Leeuwen, T. (2008). Discourse and practice: New tools for critical discourse analysis. Oxford: Oxford University Press.

Wikipedia. (2015). MV Leisure World. [Online] Available: https://en.wikipedia.org/wiki/MV_Leisure_World (June 11, 2016)

Xiao, R. (2015). Collocation. In D. Biber \& R. Reppen (Eds.), The Cambridge handbook of English corpus linguistics (pp. 106-124). Cambridge: Cambridge University Press.

Yoong, D., Tan, H. K., \& Ng, C. M. (2013). 'This is not gambling but gaming': Methods of promoting a lottery gaming company in a Malaysian daily. Discourse \& Society, 24(2), 229-247. http://dx.doi.org/10.1177/0957926512469433 